Pacific Journal of Mathematics

ABSOLUTE SUMMABILITY OF FOURIER SERIES WITH 


\title{
ABSOLUTE SUMMABILITY OF FOURIER SERIES WITH FACTORS
}

\author{
H. P. Dikshit AND A. Kumar
}

Kanno in 1969 and M. Izumi and S. Izumi in 1970 have obtained results concerning the absolute Nörlund summability of Fourier series with factors. The present paper contains theorems sharper than the aforementioned results.

1. Definitions and notations. Let $\left\{p_{n}\right\}$ be a given sequence of constants, real or complex, such that $P_{n}=\sum_{k=0}^{n} p_{k} \neq 0$ for $n \geqq 0$ and $p_{n}=P_{n}=0$, for $n<0$. A given series $\sum_{n=0}^{\infty} a_{n}$ is said to be summable $\left(N, p_{n}\right)$, if $t_{n}$ tends to a finite limit as $n \rightarrow \infty$, where

$$
t_{n}=\sum_{k=0}^{n} P_{n-k} a_{k} / P_{n}
$$

The series $\sum_{n=0}^{\infty} a_{n}$ is said to be summable $\left|N, p_{n}\right|$, if $\sum_{n=1}^{\infty}\left|t_{n}-t_{n-1}\right|<$ $\infty$. The $\left|N, p_{n}\right|$ method reduces to the $|C, \delta|$ method in the special case in which $P_{n}=A_{n}^{\delta}$, where $A_{n}^{\delta}$ is defined by the identity

$$
\sum_{n=0}^{\infty} A_{n}^{\delta} x^{n}=(1-x)^{-\delta-1},|x|<1, \delta \neq-1,-2, \cdots .
$$

Let $f(t)$ be a periodic function with period $2 \pi$ and integrable $(L)$ over $(-\pi, \pi)$ and

$$
f(t) \sim \sum_{n=1}^{\infty}\left(a_{n} \cos n t+b_{n} \sin n t\right)=\sum_{n=1}^{\infty} A_{n}(t) .
$$

We shall use the following notations throughout.

$$
\begin{gathered}
\varphi(t)=\frac{1}{2}\{f(x+t)+f(x-t)\} ; \\
R_{n}=(n+1) p_{n} / P_{n} ; S_{n}=\sum_{k=1}^{n} \frac{P_{k}}{k P_{n}} .
\end{gathered}
$$

Given a function $\lambda(t)$ and a sequence $\left\{\mu_{n}\right\}$, we write for $n=1$, $2, \cdots$,

$$
\begin{aligned}
\lambda(n) & =\lambda_{n} ; \Delta_{n} \lambda_{n}=\Delta \lambda_{n}=\lambda_{n}-\lambda_{n+1}, \\
J_{n}(\mu) & =\sum_{k=n}^{\infty} \frac{\mu_{k} \lambda_{k}}{k P_{k}},
\end{aligned}
$$

$[x]$ denotes the greatest integer not greater than $x$, in particular we write $m=[n / 2]$ and $\tau=[C / 2 t]$, for some fixed positive constant $C$. $K$ denotes a positive constant which is not necessarily the same 
at each occurrence. $\sum_{a}^{b}$ will be taken as 0 , if $a>b$.

2. Introduction and the main results. Concerning the $|C|$ summability of a Fourier series and a corresponding series with factors the following is known $([1],[8])^{1}$.

THEOREM A. For $0 \leqq \alpha<1$, and $\beta>\alpha$ the series $\sum_{n=1}^{\infty} n^{\alpha} A_{n}(x)$ is summable $|C, \beta|$, if

$$
\int_{0}^{\pi} t^{-\alpha}|d \varphi(t)| \leqq K
$$

Theorem A for $\alpha=0$ was proved by Bosanquet [1] who has also shown that the result is the best possible in the sense that $\beta$ cannot be replaced by 0 . For the other values of $\alpha$ the result was proved by Mohanty [8].

In the direction of Theorem A, M. Izumi and S. Izumi [4] have recently proved the following.

THEOREM B. Let $\left\{p_{n}\right\}$ be a positive monotonic decreasing sequence and $\lambda(t), t>0$, be a positive increasing function, then the series $\sum_{n=1}^{\infty} \lambda_{n} A_{n}(x)$ is summable $\left|N, p_{n}\right|$, if the following conditions hold.

$$
\begin{gathered}
J_{n}(1) \leqq K \lambda_{n} / P_{n}, \\
\left\{\lambda_{n} / n\right\} \text { is monotonic decreasing, }
\end{gathered}
$$

and

$$
\int_{0}^{\pi} \lambda(1 / t)|d \varphi(t)| \leqq K .
$$

With a slight modification in the proof of Theorem B as contained in [4] it may be seen that the result continues to hold even if $\lambda(t)$ is a constant function. In view of this, we may obtain Theorem A from Theorem $\mathrm{B}$ by taking $\lambda(t)=t^{\alpha}, 0 \leqq \alpha<1$. Examining the hypotheses of Theorem B closely, it appears that the condition (2.2) is indispensable. For, if $\lambda(t)=K$, then the condition (2.2) is equivalent to the boundedness of the sequence $\left\{S_{n}\right\}$ (see [2], Lemma 3) which has been shown to be a necessary condition for the $\left(N, p_{n}\right)$ summability of $\sum_{n=1}^{\infty} A_{n}(x)$ by Hille and Tamarkin ([3], Theorem II). The condition (2.4), of course corresponds to the condition (2.1) of Theorem A. The following theorem, which we prove in the present paper, shows that condition (2.3) is redundant in Theorem $B$.

1 We write $\int_{0}^{\pi}$ for $\lim _{\varepsilon \rightarrow 0} \int_{\varepsilon}^{\pi}$. 
THEOREM 1. Let $\lambda(t), t>0$, be a positive nondecreasing function and $\left\{p_{n}\right\}$ be a positive monotonic nonincreasing sequence such that (2.2) holds and for some positive constant $C$

$$
\int_{0}^{\pi} \lambda(C / t)|d \varphi(t)| \leqq K,
$$

then $\sum_{n=1}^{\infty} \lambda_{n} A_{n}(x)$ is summable $\left|N, p_{n}\right|$.

Lemma 6 of the present paper shows the role that a specific choice of $\lambda(t)$ plays in $\left(2.4^{\prime}\right)$.

Another generalisation of Theorem A, in the form of the following theorem is due to Kanno [5].

THEOREM C. Let $\left\{p_{n}\right\}$ and $\left\{\Delta p_{n}\right\}$ are both nonnegative and nonincreasing and $\lambda(t), t>0$, be a positive nondecreasing function such that $\left\{\lambda_{n} / P_{n}\right\}$ is nonincreasing. Then the series $\sum_{n=1}^{\infty} R_{n} \lambda_{n} A_{n+1}(x)$ is summable $\left|N, p_{n}\right|$, if $\left(2.4^{\prime}\right)$ holds and

$$
J_{n}(R) \leqq K \lambda_{n} / P_{n} .
$$

Dropping the condition that $\left\{\Delta p_{n}\right\}$ is nonincreasing and replacing the condition: ' $\left\{\lambda_{n} / P_{n}\right\}$ is nonincreasing' by the condition: ' $\left\{\lambda_{n} p_{n} / P_{n}\right\}$ is nonincreasing' which appears to be lighter than the former, we obtain the following more refined result than Theorem $\mathrm{C}$ whenever $P_{n} \rightarrow \infty$.

THEOREM 2. Let $\left\{p_{n}\right\}$ be nonnegative nonincreasing sequence with $P_{n} \rightarrow \infty$ as $n \rightarrow \infty$ and $\lambda(t), t>0$, be a positive nondecreasing function such that $\left\{\lambda_{n} p_{n} / P_{n}\right\}$ is nonincreasing and (2.5) holds. Then the series $\sum_{n=1}^{\infty} R_{n} \lambda_{n} A_{n+1}(x)$ is summable $\left|N, p_{n}\right|$, if $\left(2.4^{\prime}\right)$ holds.

In order to consider the remaining case of Theorem $\mathrm{C}$ in which $P_{n} \rightarrow l$ (finite) as $n \rightarrow \infty$, we observe that in this case (2.5) implies that

$$
\sum_{k=1}^{\infty} \frac{R_{k} \lambda_{k}}{k}<\infty
$$

Further, since $\lambda(t)$ is positive nondecreasing, $\left(2.4^{\prime}\right)$ implies that

$$
\int_{0}^{\pi}|d \varphi(t)| \leqq K
$$

Thus, applying Lemma 7 with $\varepsilon_{k}=R_{k} \lambda_{k}$, we obtain the absolute convergence of $\sum_{k=1}^{\infty} R_{k} \lambda_{k} A_{k+1}(x)$ which $a$ fortiori implies its $\left|N, p_{n}\right|$ summability, since by virtue of Lemma 3 , the method is absolutely 
regular whenever $\left\{p_{n}\right\}$ is nonnegative nonincreasing. Thus, a sharper result under lighter assumptions is obtained for this case.

It may be observed that Theorem 2 and Theorem 1, which include Theorem $\mathrm{C}$ when $P_{n} \rightarrow \infty$ and Theorem B respectively, are established by a unified proof shorter than the existing proofs of Theorem $B$ and Theorem C. For some interesting corollaries of Theorem $\mathrm{C}$ and $a$ fortiori of Theorem 2 reference may be made to [5].

3. Preliminary results. We need the following lemmas for the proof of our theorems.

LEMMA 1. Let $\left\{a_{n}\right\}$ be a given sequence, then for any $x$, we have

$$
(1-x) \sum_{k=r}^{s} a_{k} x^{k}=a_{r} x^{r}-a_{s} x^{s+1}-\sum_{k=r}^{s-1} \Delta a_{k} x^{k+1},
$$

where $r$ and $s$ are integers such that $s \geqq r \geqq 0$.

LEMMA 2. If $\left\{q_{n}\right\}$ is a nonnegative nonincreasing sequence such that $Q_{n}=\sum_{k=0}^{n} q_{k}$, then for $0 \leqq a \leqq b \leqq \infty$ and any $n$,

$$
\left|\sum_{k=a}^{b} q_{k} \exp i(n-k) t\right| \leqq K Q_{\tau},
$$

uniformly in $0<t \leqq \pi$.

Lemma 2 follows from the proof of Lemma (5.11) of [7], when we take $\tau=[C / 2 t]$ in place of $[1 / t]$.

LEMMA 3. If $\left\{p_{n}\right\}$ is nonnegative nonincreasing, then for all $k \geqq 0$ and $1 \leqq a \leqq b \leqq \infty$,

$$
\sum_{n=a}^{b} P(n, k)=\sum_{n=a}^{b}\left(\frac{P_{n-k}}{P_{n}}-\frac{P_{n-k-1}}{P_{n-1}}\right) \leqq 1
$$

and for any $n>0, P(n, k) \geqq 0$ so that the $\left(N, p_{n}\right)$ method is absolutely regular.

Proof. We have

$$
\sum_{n=a}^{b}\left(\frac{P_{n-k}}{P_{n}}-\frac{P_{n-k-1}}{P_{n-1}}\right)=\frac{P_{b-k}}{P_{b}}-\frac{P_{a-k-1}}{P_{a-1}} \leqq 1 .
$$

For, $n>0$ we observe that

$$
P(n, k)=\frac{p_{n-k} P_{n}-p_{n} P_{n-k}}{P_{n} P_{n-1}} \geqq 0,
$$


since $\left\{p_{n}\right\}$ is nonnegative nonincreasing. It is known [6] that necessary and sufficient conditions for the absolute regularity of the $\left(N, p_{n}\right)$ method are that

$$
p_{n-k} / P_{n} \longrightarrow 0 \text { as } n \longrightarrow \infty \text { and } \sum_{n=1}^{\infty}|P(n, k)| \leqq K
$$

for all $k$. The latter of these conditions is already proved while the former follows from the fact that $(k+1) p_{k} \leqq P_{k}$.

LEMMA 4. If $\left\{p_{n}\right\}$ is nonnegative nonincreasing, then

(i) for any positive integer $r, P_{r n} \leqq r P_{n}$ and, if in addition $\left\{\lambda_{n}\right\}$ is nonnegative nondecreasing such that (2.2) holds, or $P_{n} \rightarrow \infty$ with $n$ and (2.5) holds, then

(ii) $\lambda_{2 n} \leqq K \lambda_{n}$.

Proof. Using the hypothesis that $\left\{p_{n}\right\}$ is nonnegative and nonincreasing, we write

$$
P_{r n} \leqq \sum_{\nu=1}^{r} \sum_{k=(\nu=1) n}^{\nu n} p_{k} \leqq \sum_{\nu=1}^{r} P_{n}=r P_{n} .
$$

This proves (i). Next, if $\left\{\mu_{n}\right\}$ is a nonnegative sequence, then for $\rho \geqq 2 n$,

$$
J_{n}(\mu) \geqq J_{2 n}(\mu) \geqq \lambda_{2 n} \sum_{k=2 n}^{\rho} \frac{\mu_{k}}{k P_{k}},
$$

since $\left\{\lambda_{n}\right\}$ is nondecreasing. Taking $\rho=3 n$ and $\mu_{n}=1$ for all $n$ and observing that $\left\{P_{n}\right\}$ is positive nondecreasing, we have

$$
J_{n}(1) \geqq \frac{(n+1) \lambda_{2 n}}{3 n P_{3 n}} \geqq \frac{1}{9} \frac{\lambda_{2 n}}{P_{n}},
$$

by virtue of the result (i). Similarly, since

$$
\frac{R_{k}}{k P_{k}} \geqq \frac{p_{k+1}}{P_{k} P_{k+1}}=\frac{1}{P_{k}}-\frac{1}{P_{k+1}} \geqq 0,
$$

taking $\rho \rightarrow \infty$ and $\mu_{n}=R_{n}$, we get

$$
J_{n}(R) \geqq \frac{\lambda_{2 n}}{P_{2 n}} \geqq \frac{1}{2} \frac{\lambda_{2 n}}{P_{n}} .
$$

In view of the inequalities (3.1) and (3.2) and the hypotheses (2.2), (2.5), we have

$$
K \frac{\lambda_{n}}{P_{n}} \geqq 9 J_{n}(\mu) \geqq \frac{\lambda_{2 n}}{P_{n}},
$$


where $\mu_{n}=1$ or $\mu_{n}=R_{n}$. This gives the result (ii) and thus we complete the proof of the lemma.

LEMMA 5. If $\left\{p_{n}\right\}$ is nonnegative nonincreasing and $\left\{\lambda_{n}\right\}$ is positive nondecreasing such that (2.2) holds, then for all $N \geqq n$,

$$
n \sum_{k=n}^{N}\left|\Delta\left(\lambda_{k} / k\right)\right| \leqq K \lambda_{n}, \quad n=1,2, \cdots
$$

Proof. We first observe that $\left\{n / P_{n}\right\}$ is nondecreasing. For,

$$
\Delta\left(\frac{P_{n}}{n}\right)=\frac{1}{n(n+1)}\left\{P_{n}-n p_{n+1}\right\} \geqq 0,
$$

since $\left\{p_{n}\right\}$ is nonnegative nonincreasing. Thus, under the hypothesis (2.2), we have

$$
K \lambda_{n} \geqq P_{n} \sum_{k=n}^{\infty} \frac{\lambda_{k}}{k P_{k}} \geqq n \sum_{k=n}^{\infty} \frac{\lambda_{k}}{k^{2}} .
$$

Further, if $N \geqq n$, then

$$
n \frac{\lambda_{N+1}}{N+1}=n \lambda_{N+1} \sum_{k=N+1}^{\infty} \frac{1}{k(k+1)} \leqq n \sum_{k=n}^{\infty} \frac{\lambda_{k}}{k(k+1)},
$$

since $\left\{\lambda_{n}\right\}$ is positive and nondecreasing. Thus,

$$
\begin{aligned}
n \sum_{k=n}^{N}\left|\Delta\left(\frac{\lambda_{k}}{k}\right)\right| & \leqq n \sum_{k=n}^{N} \frac{\lambda_{k+1}-\lambda_{k}}{k+1}+n \sum_{k=n}^{N} \frac{\lambda_{k}}{k(k+1)} \\
& =2 n \sum_{k=n}^{N} \frac{\lambda_{k}}{k(k+1)}+n \frac{\lambda_{N+1}}{N+1}-\lambda_{n} \\
& \leqq 3 n \sum_{k=n}^{\infty} \frac{\lambda_{k}}{k(k+1)} \leqq K \lambda_{n}
\end{aligned}
$$

by virtue of (3.3) and (3.4). This completes the proof of the lemma.

LEMMA 6. Let $\theta(t)$ and $\lambda(t)$ be two nonnegative nondecreasing functions such that $\theta(n)=\lambda(n)=\lambda_{n}$. Let $a$ and $b$ be two positive numbers such that

$$
I(\theta, \varepsilon)=\int_{\varepsilon}^{\pi} \theta(a / t)|d \varphi(t)| \quad \text { and } \quad I(\lambda, \varepsilon)=\int_{\varepsilon}^{\pi} \lambda(b / t)|d \varphi(t)|
$$

exist, for every $\varepsilon>0$. If $\lambda_{2 n} \leqq K \lambda_{n}$, then $I(\theta, 0)<\infty$ if and only if $I(\lambda, 0)<\infty$.

Proof. We assume without loss of generality that $a \leqq b$. Thus, for $0<t \leqq b$, we have 


$$
a / t \leqq b / t \leqq 2[b / t]
$$

and, therefore, using the hypotheses that $\theta(t)$ and $\lambda(t)$ are nondecreasing, we have

$$
\theta(a / t) \leqq \lambda(2[b / t]) \leqq K \quad \lambda(b / t),
$$

since $\theta(n)=\lambda(n)$ and $\lambda_{2 n} \leqq K \lambda_{n}$. Now taking $0<t \leqq a$, we have for some fixed integer $r$

$$
b / t \leqq 2^{r}[a / t]
$$

and, therefore,

$$
\lambda(b / t) \leqq K \lambda([a / t])=K \theta(a / t) .
$$

The lemma readily follows from (3.5) and (3.6).

LEMMA 7. If $\sum_{n=1}^{\infty}\left(\left|\varepsilon_{n}\right| / n\right)<\infty$ and $\int_{0}^{\pi}|d \varphi(t)| \leqq K$, then

$$
\sum_{n=1}^{\infty}\left|\varepsilon_{n} A_{n+1}(x)\right|<\infty \text {. }
$$

Proof. Since $\int_{0}^{\pi}|d \varphi(t)| \leqq K$, we have by integration by parts,

$$
\left|A_{n}(x)\right|=\left|\frac{2}{\pi} \int_{0}^{\pi} \frac{\sin n t}{n} d \varphi(t)\right| \leqq \frac{1}{n} \int_{0}^{\pi}|d \varphi(t)| \leqq \frac{K}{n} .
$$

The desired result now follows directly.

4. Proof of Theorem 1 and Theorem 2. If $t_{n}$ denotes the $n$th $\left(N, p_{n}\right)$ mean of $\sum_{n=1}^{\infty} A_{n}(x) \mu_{n} \lambda_{n}$, then

$$
t_{n}-t_{n-1}=\frac{2}{\pi} \int_{0}^{\pi} \varphi(t) g(n, t) d t
$$

where

$$
g(n, t)=\sum_{k=1}^{n} P(n, k) \mu_{k} \lambda_{k} \cos k t,
$$

$\mu_{k}=1$ or $R_{k}$ and $P(n, k)$ is defined by Lemma 3 .

Integrating by parts, we get

$$
\int_{0}^{\pi} \varphi(t) g(n, t) d t=-\int_{0}^{\pi}\left(\int_{0}^{t} g(n, u) d u\right) d \varphi(t)
$$

and, therefore, 


$$
\sum_{n=1}^{\infty}\left|t_{n}-t_{n-1}\right| \leqq \sum_{n=1}^{\infty} \int_{0}^{\pi}\left|\int_{0}^{t} g(n, u) d u\right||d \varphi(t)|
$$

Thus, using the hypothesis $\left(2.4^{\prime}\right)$, we observe that in order to prove the $\left|N, p_{n}\right|$ summability of $\sum_{n=1}^{\infty} \mu_{n} \lambda_{n} A_{n}(x)$, it is sufficient to show that uniformly in $0<t \leqq \pi$,

$$
\Sigma=\sum_{n=1}^{\infty}\left|\sum_{k=1}^{n} P(n, k) \lambda_{k} \mu_{k} k^{-1} \sin k t\right| \leqq K \lambda(C / t) .
$$

We write

$$
\begin{aligned}
\Sigma= & \sum_{n=1}^{2 \tau+1}\left|\sum_{k=1}^{n} P(n, k) k^{-1} \lambda_{k} \mu_{k} \sin k \mathrm{t}\right| \\
& +\sum_{n=2 \tau+2}^{\infty}\left|\left(\sum_{k=1}^{\tau}+\sum_{k=\tau+1}^{n}\right) P(n, k) k^{-1} \lambda_{k} \mu_{k} \sin k t\right| \\
\leqq & \Sigma_{1}+\Sigma_{2}+\Sigma_{3},
\end{aligned}
$$

say. Now, we observe that

$$
\lambda(2 \tau+1) \leqq K \lambda(C / t) .
$$

For, if $\tau \geqq 1$, then $2 \tau+1<2^{2} \tau$ and (4.3) follows from the result (ii) of Lemma 4 and the hypothesis that $\lambda(t)$ is a positive nondecreasing function. The latter also implies (4.3) directly when $\tau=0$.

Since $|\sin k t| \leqq k t$, we have by a change in order of summations and Lemma 3

$$
\begin{aligned}
\Sigma_{1} & \leqq t \sum_{k=1}^{2 \tau+1} \mu_{k} \lambda_{k} \sum_{n=k}^{2 \tau+1} P(n, k) \\
& \leqq t \sum_{k=1}^{2 \tau+1} \mu_{k} \lambda_{k} \leqq K \lambda(C / t),
\end{aligned}
$$

by virtue of (4.3). Again writing $|\sin k t| \leqq k t$ and applying the result of Lemma 3, we get

$$
\begin{aligned}
\Sigma_{2} & \leqq t \sum_{n=2 \tau+2}^{\infty} \sum_{k=1}^{\tau} P(n, k) \mu_{k} \lambda_{k} \\
& =t \sum_{k=1}^{\tau} \mu_{k} \lambda_{k} \sum_{n=2 \tau+2}^{\infty} P(n, k) \leqq K \lambda(C / t) .
\end{aligned}
$$

In order to estimate $\Sigma_{3}$, we consider the following sum and write for a sufficiently large $N$,

$$
\begin{aligned}
\Sigma^{*} & =\sum_{n=2 \tau+2}^{N}\left|\sum_{k=\tau+1}^{n} P(n, k) k^{-1} \lambda_{k} \mu_{k} \exp (i k t)\right| \\
& =\sum_{n=2 \tau+2}^{N}\left|\left(\sum_{k=\tau+1}^{m}+\sum_{k=m+1}^{n}\right) P(n, k) k^{-1} \lambda_{k} \mu_{k} \exp (i k t)\right| \\
& \leqq \Sigma_{1}^{*}+\Sigma_{2}^{*}
\end{aligned}
$$


say. Applying first, Lemma 1 with $x=\exp (i t)$ and then effecting suitable changes in order of summations, we get

$$
\begin{aligned}
\Sigma_{1}^{*} \leqq & K t^{-1} \sum_{n=2 \tau+2}^{N} \sum_{k=\tau+1}^{m-1}\left|\left\{\Delta_{k}(P(n, k)) \mu_{k} k^{-1} \lambda_{k}+P(n, k+1) \Delta\left(k^{-1} \mu_{k} \lambda_{k}\right)\right\}\right| \\
& +K t^{-1} \sum_{n=2 \tau+2}^{N} P(n, m) \mu_{m} \lambda_{m} m^{-1}+K \sum_{n=2 \tau+2}^{N} P(n, \tau+1) \mu_{\tau+1} \lambda_{\tau+1} \\
\leqq & K t^{-1} \sum_{k=\tau+1}^{N} k^{-1} \mu_{k} \lambda_{k} \sum_{n=2 k+1}^{N}\left|\Delta_{k}(P(n, k))\right| \\
& +K t^{-1} \sum_{k=\tau+1}^{N}\left|\Delta\left(k^{-1} \mu_{k} \lambda_{k}\right)\right| \sum_{n=2 k+1}^{N} P(n, k+1) \\
& +K t^{-1} \sum_{n=2 \tau+2}^{N} m^{-1} \mu_{m} \lambda_{m}\left(\frac{p_{n-m}}{P_{n}}-\frac{p_{n} P_{n-m-1}}{P_{n} P_{n-1}}\right) \\
& +K \lambda_{\tau+1} \sum_{n=2 \tau+2}^{N} P(n, \tau+1) \\
& =\Sigma_{11}^{*}+\Sigma_{12}^{*}+\Sigma_{13}^{*}+\Sigma_{14}^{*},
\end{aligned}
$$

say. Since, due to nonnegative nonincreasing nature of $\left\{p_{n}\right\}-$ $\Delta_{k} P(n, k) \geqq 0$, for relevant values of $k$, we have

$$
\begin{aligned}
\Sigma_{11}^{*} & =K t^{-1} \sum_{k=\tau+1}^{N} k^{-1} \mu_{k} \lambda_{k} \sum_{n=2 k+1}^{N}\left(\frac{p_{n-k-1}}{P_{n-1}}-\frac{p_{n-k}}{P_{n}}\right) \\
& \leqq K t^{-1} \sum_{k=\tau+1}^{N} k^{-1} \mu_{k} \lambda_{k} \frac{p_{k}}{P_{2 k}} \\
& \leqq K t^{-1} p_{\tau+1} J_{\tau+1}(\mu) \leqq K \lambda(C / t),
\end{aligned}
$$

by virtue of (4.3), the hypothesis (2.2) or (2.5) and the fact that $\left\{R_{n}\right\} \in B$.

First taking $\mu_{n}=1$, we have by Lemma 3 and Lemma 5 with (4.3)

$$
\Sigma_{12}^{*} \leqq K t^{-1} \sum_{k=\tau+1}^{N}\left|\Delta\left(\lambda_{k} / k\right)\right| \leqq K \lambda(C / t) .
$$

Next, when $\mu_{n}=R_{n}$, that is, in the case of Theorem 2, we have

$$
\begin{aligned}
\sum_{12}^{*} & \leqq K t^{-1} \sum_{k=\tau+1}^{N}\left|\Delta\left(\frac{k+1}{k} \frac{\lambda_{k} p_{k}}{P_{k}}\right)\right| \\
& \leqq K R_{\tau+1} \lambda(C / t) \leqq K \lambda(C / t),
\end{aligned}
$$

by virtue of the hypothesis that $\left\{\lambda_{n} p_{n} / P_{n}\right\}$ is nonincreasing and the result (4.3). Now,

$$
\begin{aligned}
\Sigma_{13}^{*} & \leqq K t^{-1} \sum_{n=2 \tau+2}^{N} m^{-1} \mu_{m} \lambda_{m} p_{m} \frac{1}{P_{m}} \\
& \leqq K t^{-1} p_{\tau+1} J_{\tau+1}(\mu) \leqq K \lambda(C / t),
\end{aligned}
$$


by virtue of (4.3), the hypothesis (2.2) or (2.5) and the fact that $\left\{R_{n}\right\} \in B$. Further applying Lemma 3 and using (4.3), we directly get

$$
\Sigma_{14}^{*} \leqq K \lambda(C / t)
$$

Writing

$$
P(n, k)=\frac{p_{n-k}}{P_{n}}-\frac{p_{n} P_{n-k-1}}{P_{n} P_{n-1}}
$$

we have

$$
\begin{aligned}
\Sigma_{2}^{*} \leqq & \sum_{n=2 \tau+2}^{N} \frac{1}{P_{n}}\left|\sum_{k=m+1}^{n} p_{n-k} \lambda_{k} k^{-1} \mu_{k} \exp (i k t)\right| \\
& +\sum_{n=2 \tau+2}^{N} \frac{p_{n}}{P_{n} P_{n-1}}\left|\sum_{k=m+1}^{n} P_{n-k-1} \lambda_{k} k^{-1} \mu_{k} \exp (i k t)\right| .
\end{aligned}
$$

Observing that $\left\{k^{-1} \mu_{k}\right\}$ is nonincreasing and applying Abel's lemma, we obtain by Lemma 2

$$
\begin{aligned}
\Sigma_{2}^{*} \leqq & K \sum_{n=2 \tau+2}^{N} \frac{1}{P_{n}} \lambda_{n} m^{-1} \mu_{m} \max _{m<\nu \leqq n}\left|\sum_{k=m+1}^{\nu} p_{n-k} \exp (i k t)\right| \\
& +K \sum_{n=2 \tau+2}^{N} \frac{p_{n}}{P_{n} P_{n-1}} P_{m} \lambda_{n} m^{-1} \mu_{m} \max _{m<\nu \leqq n}\left|\sum_{k=m+1}^{\nu} \exp (i k t)\right| \\
\leqq & K\left(P_{\tau}+(\tau+1) p_{2 \tau+2}\right) J_{\tau+1}(\mu) \leqq K \lambda(C / t),
\end{aligned}
$$

by virtue of Lemma 4 and the hypothesis (2.2) or (2.5) with (4.3).

Combining (4.6) (4.12), we prove that $\Sigma^{*} \leqq K \lambda(C / t)$ which in its turn implies that $\Sigma_{3} \leqq K \lambda(C / t)$. The last result combined with (4.2), (4.4) and (4.5) shows that (4.1) is valid and we have, thus proved the $\left|N, p_{n}\right|$ summability of $\sum_{n=1}^{\infty} \mu_{n} \lambda_{n} A_{n}(x)$. Observing that the above proof remains unaffected, if $A_{n}(x)$ is replaced by $A_{n+1}(x)$, we conclude the $\left|N, p_{n}\right|$ summability of $\sum_{n=1}^{\infty} \mu_{n} \lambda_{n} A_{n+1}(x)$.

This completes the proof of our theorems.

The authors should like to thank the referee for suggesting Lemma 6 and Lemma 7 which have helped to improve the presentation of the paper.

\section{REFERENCES}

1. L. S. Bosanquet, Note on the absolute summability (C) of a Fourier series, J. London Math. Soc., 11 (1936), 11-15.

2. H. P. Dikshit and A. Kumar, Absolute total-effective $\left(N, p_{n}\right)$ means $I$, Proc. Cambridge Phil. Soc., 77 (1975), 103-108.

3. E. Hille and J. D. Tamarkin, On the summability of Fourier series I, Trans. Amer. Math. Soc., 34 (1932), 757-783.

4. M. Izumi and S. Izumi, Absolute Nörlund summability facter of Fourier series, Proc. Japan Acad., 46 (1970), 642-646. 
5. K. Kanno, On the absolute Nörlund summability of the factored Fourier series, Tôhoku Math. J., 21 (1969), 434-447.

6. B. Kwee, Absolute regularity of the Nörlund means, J. Aust. Math. Soc., 5 (1965), 1-7.

7. L. McFadden, Absolute Nörlund summability, Duke Math. J., 9 (1942), 168-207.

8. R. Mohanty, The absolute Cesàro summability of some series associated with Fourier series and its allied series, J. London Math. Soc., 25 (1950), 63-67.

Received October 30, 1974 and in revised form July 16, 1975.

UNIVERSITY OF JABALPUR 



\section{PACIFIC JOURNAL OF MATHEMATICS}

\section{EDITORS}

RICHARD ARENS (Managing Editor) University of California

Los Angeles, California 90024

\section{R. A. BEAUMONT}

University of Washington Seattle, Washington 98105
J. DugundjI Department of Mathematics University of Southern Californı Los Angeles, California 90007

D. Gilbarg AND J. Milgram Stanford University Stanford, California 94305

\section{ASSOCIATE EDITORS}

E. F. BECKENBACH

B. H. NeUMANN

F. WOLF

K. YosHidA

\section{SUPPORTING INSTITUTIONS}

UNIVERSITY OF BRITISH COLUMBIA CALIFORNIA INSTITUTE OF TECHNOLOGY UNIVERSITY OF CALIFORNIA MONTANA STATE UNIVERSITY UNIVERSITY OF NEVADA NEW MEXICO STATE UNIVERSITY OREGON STATE UNIVERSITY UNIVERSITY OF OREGON OSAKA UNIVERSITY

\author{
UNIVERSITY OF SOUTHERN CALIFORNIA \\ STANFORD UNIVERSITY \\ UNIVERSITY OF TOKYO \\ UNIVERSITY OF UTAH \\ WASHINGTON STATE UNIVERSITY \\ UNIVERSITY OF WASHINGTON \\ AMERICAN MATHEMATICAL SOCIETY \\ NAVAL WEAPONS CENTER
}




\section{Pacific Journal of Mathematics}

\section{Vol. 61, No. $1 \quad$ November, 1975}

Jiří Adámek, V. Koubek and Věra Trnková, Sums of Boolean spaces represent every

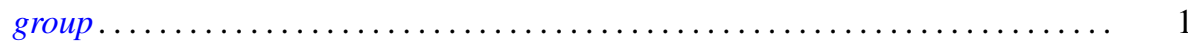

Richard Neal Ball, Full convex l-subgroups and the existence of $a^{*}$-closures of

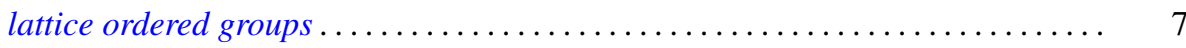

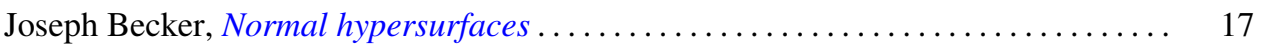

Gerald A. Beer, Starshaped sets and the Hausdorff metric . . . . . . . . . . . . . 21

Dennis Dale Berkey and Alan Cecil Lazer, Linear differential systems with

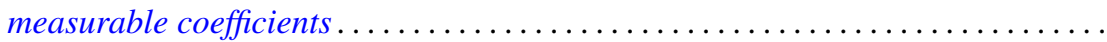

Harald Boehme, Glättungen von Abbildungen 3-dimensionaler

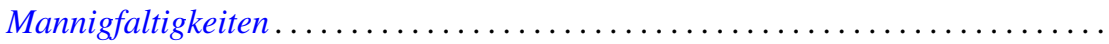

Stephen LaVern Campbell, Linear operators for which $T^{*} T$ and $T+T^{*}$

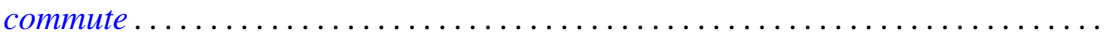

H. P. Dikshit and Arun Kumar, Absolute summability of Fourier series with

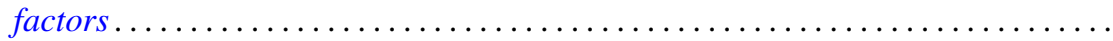

Andrew George Earnest and John Sollion Hsia, Spinor norms of local integral

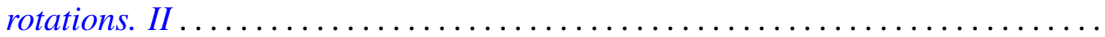

Erik Maurice Ellentuck, Semigroups, Horn sentences and isolic structures .........

Ingrid Fotino, Generalized convolution ring of arithmetic functions . . . . . . . . . . .

Michael Randy Gabel, Lower bounds on the stable range of polynomial rings .......

Fergus John Gaines, Kato-Taussky-Wielandt commutator relations and

characteristic curves

Theodore William Gamelin, The polynomial hulls of certain subsets of $C^{2}$

R. J. Gazik and Darrell Conley Kent, Coarse uniform convergence spaces. . .

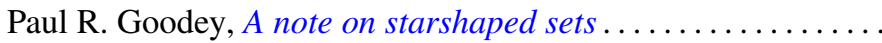

Eloise A. Hamann, On power-invariance

M. Jayachandran and M. Rajagopalan, Scattered compactification for $N \cup\{P\}$. . .

V. Karunakaran, Certain classes of regular univalent functions .

John Cronan Kieffer, A ratio limit theorem for a strongly subadditive set function in a locally compact amenable group .................

Siu Kwong Lo and Harald G. Niederreiter, Banach-Buck measure, density, and uniform distribution in rings of algebraic integers ........

Harold W. Martin, Contractibility of topological spaces onto metric spaces ....

Harold W. Martin, Local connectedness in developable spaces .

A. Meir and John W. Moon, Relations between packing and covering numbers of a tree.

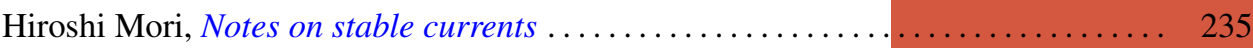

Donald J. Newman and I. J. Schoenberg, Splines and the logarithmic function . . . . 241

M. Ann Piech, Locality of the number of particles operator....

Fred Richman, The constructive theory of $K T$-modules .......

Gerard Sierksma, Carathéodory and Helly-numbers of

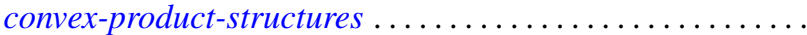

Raymond Earl Smithson, Subcontinuity for multifunctions .... . . 